\title{
Ectopic expression of Id1 or Id3 inhibits transcription of the GATA-4 gene in P19CL6 cells under differentiation condition
}

\author{
Yumei Yokura-Yamada ${ }^{1}$, Makoto Araki ${ }^{2}$, Masatomo Maeda, ${ }^{1, *}$ \\ 'Graduate School of Pharmaceutical Sciences, Osaka University, Suita, Osaka, Japan; \\ ${ }^{2}$ Meiji Pharmaceutical University, Tokyo, Japan.
}

SUMMARY Inhibitor of DNA binding (Id) is a dominant negative form of the E-box binding basic-helixloop-helix (bHLH) transcription factor since it is devoid of the basic region required for DNA binding and forms an inactive hetero dimer with bHLH proteins. The E-box sequence located in the promoter region of the GATA-binding protein $4(G A T A-4)$ gene is essential for transcriptional activation in P19CL6 cells. These cells differentiate into cardiomyocytes and start to express GATA4 , which further triggers cardiac-specific gene expression. In this study, expression plasmids for Ids tagged with human influenza hemagglutinin (HA)-FLAG were constructed and introduced into P19CL6 cells. The stable clones expressing the recombinant Id proteins (Id1 or Id3) were isolated. The GATA-4 gene expression in these clones under differentiation condition in the presence of $1 \%$ dimethyl sulfoxide (DMSO) was repressed, with concomitant abolishment of the transcription of $\alpha$-myosin heavy chain ( $\alpha$-MHC), which is a component of cardiac myofibrils. Thus, the increased expression of Id protein could affect GATA-4 gene expression and negatively regulate the differentiation of P19CL6 cells.

Keywords Inhibitor of DNA binding, GATA transcription factor, cardiomyocyte differentiation, transcription

\section{Introduction}

It is well known that many gene products participate spatio-temporally in a complex manner in the developmental process $(1)$. In mouse heart formation, transcription factor GATA-binding protein 4 (GATA4) together with NK2 homeobox 5 (Nkx2.5) and T-box factor 5 (Tbx5), and chromatin remodeling protein SMARCD3 (BAF60c) are key upstream regulators of cardiomyocyte differentiation in the cardiogenic splanchnic mesoderm (2). Expression of GATA-4 in the extraembryonic endoderm in the embryo is required for folding morphogenesis to form a primitive heart tube and foregut (3). Consistent with the expression of GATA-4 in cardiomyocytes at all stages of cardiac development in mouse (4), it is reported that mutations of the GATA-4 gene lead to variable phenotypes of human congenital heart diseases (5).

To study cardiomyocyte differentiation at the cellular level, P19 mouse embryonic carcinoma cells and their derivative P19CL6 cells have been used because they easily start differentiating into beating cardiomyocytes upon the addition of dimethyl sulfoxide (DMSO) (6). It was further demonstrated that expression of the GATA-4 gene is required for the differentiation of cardiomyocytes
(7). As for transcriptional regulation, the GATA-4 gene is transcribed from two alternative 5 ' untranslated exons (E1a and E1b) $(8,9)$, and the level of the E1a transcript of mouse heart is 20-times higher than that of E1b (8). Analyses of the promoter for E1a demonstrated that the conserved E-box sequence (CACGTG) is essential for transcription from the E1a exon $(10,11)$, suggesting that the basic-helix-loop-helix (bHLH) transcription factor(s) may play a role in transcription of the GATA-4 gene $(9,12)$. It is also reported that more euchromatic state of the further upstream region of the cluster of GC-boxes and E-box activates the GATA-4 promoter (13).

The inhibitor of DNA binding (Id) proteins (Id1Id4) which do not have the amino-terminal basic region of bHLH transcription factor function as a dominant negative form of bHLH proteins, and their functions seem to be redundant or compensatory although Ids are required for heart development (14). Ids are also suggested to play a role in keeping precursor cells immature and expanding the cell population size during development (15). Id1 and Id3, although the latter is less active, are essential for specification of mesendosomal progenitors into cardiac progenitors in the first heart field (16). Biochemical studies further demonstrated that Id1, Id2 and Id 3 bind GATA-4 and Nkx2.5 proteins and 
inhibit their synergistic transcriptional activation due to inhibition of DNA binding and/or mutual interaction (17). Stable expression of Id3 ectopically in P19 cells inhibited the differentiation concomitant decrease of GATA-4 expression (17). In this study we constructed expression plasmids for tagged-Id1, Id 2 and Id3, and tried to express these tagged proteins stably in P19CL6 cells to determine whether their differentiation into cardiomyocytes is inhibited or not.

\section{Materials and Methods}

\subsection{Cell culture}

P19CL6 cells (RIKEN Cell Bank, Tsukuba, Ibaraki, Japan) were cultured at $37^{\circ} \mathrm{C}$ in $\alpha$-Eagle's minimal essential medium (MEM) (Sigma, St. Louis, MO, USA) containing $10 \%(\mathrm{v} / \mathrm{v})$ fetal bovine serum (FBS) (GIBCO BRL, Gaithersburg, MD, USA) and antibiotics [2.5 $\mu \mathrm{g} / \mathrm{ml}$ fungizon (GIBCO BRL), 100 units $/ \mathrm{mL}$ benzylpenicillin (Wako, Osaka, Japan), and $100 \mu \mathrm{g} / \mathrm{mL}$ streptomycin sulfate (Wako)]. Cells $\left(1 \times 10^{5}\right.$ cells in $\Phi 10$ $\mathrm{cm}$ dish) were allowed to differentiate in the presence of $1 \%(\mathrm{v} / \mathrm{v})$ DMSO (Wako) (10). The medium was changed 4 days after inoculation and then every 2 days.

\subsection{Analysis of RNA}

Total cellular RNA was extracted with Isogen (Nippon Gene, Toyama, Japan) from a $\Phi 10 \mathrm{~cm}$ dish according to the manufacturer's protocol, and an aliquot (5 $\mu \mathrm{g})$ was reverse transcribed with Moloney Murine Leukemia Virus (M-MLV) Reverse Transcriptase
(TaKaRa, Kusatsu, Shiga, Japan) and the oligo(dT) $)_{15}$ primer in a volume of $20 \mu \mathrm{L}$. After RNase H (TaKaRa) treatment, cDNA $(0.3 \mu \mathrm{L})$ was subjected to semiquantitative PCR analysis (18) with GoTaq $^{\circledR}$ DNA polymerase (Promega, Madison, WI, USA). The unsaturated conditions for polymerase chain reaction (PCR) comprised preheating $\left(94^{\circ} \mathrm{C}, 3 \mathrm{~min}\right)$, followed by $17-27$ cycles of denaturation $\left(94^{\circ} \mathrm{C}, 0.5 \mathrm{~min}\right)$, annealing $\left(55-61^{\circ} \mathrm{C}, 0.5 \mathrm{~min}\right)$, and extension $\left(72^{\circ} \mathrm{C}, 0.5 \mathrm{~min}\right)$, and then post-incubation $\left(72^{\circ} \mathrm{C}, 5 \mathrm{~min}\right)$ : typically, GATA-4 (27 cycles, $\left.55^{\circ} \mathrm{C}\right), \alpha$-myosin heavy chain $(\alpha-\mathrm{MHC})(24$ cycles, $\left.60^{\circ} \mathrm{C}\right), \operatorname{Id} 1\left(21\right.$ cycles, $\left.61^{\circ} \mathrm{C}\right), \operatorname{Id} 2(21$ cycles, $\left.60^{\circ} \mathrm{C}\right), \mathrm{Id} 3\left(21\right.$ cycles, $\left.60^{\circ} \mathrm{C}\right)$, and $\beta$-actin $(17$ cycles, $60^{\circ} \mathrm{C}$ ). The primer pairs used for PCR are shown in Table 1A. The PCR products were size-separated by $2 \%(\mathrm{w} / \mathrm{v})$ agarose gel-electrophoresis, and DNA bands were visualized with ethidium bromide. Images were recorded with a FAS-III UV-imaging system (Toyobo, Osaka, Japan).

\subsection{Cloning of cDNAs for mouse Id1, Id2 and Id3}

P19CL6 cells were cultured for 12 days in the presence of $1 \%(\mathrm{v} / \mathrm{v})$ DMSO. cDNA was synthesized from total cellular RNA as prepared in 2.2., and was subjected to PCR using a primer pair [YY001/YY002 to amplify cDNA for the coding region of Id1 cDNA, YY003/ YY002 for Id2, or YY005/YY006 for Id3 (Table 1B)] and GoTaq ${ }^{\circledR}$ DNA polymerase. The PCR conditions were [preheating $\left(94^{\circ} \mathrm{C}, 3 \mathrm{~min}\right)$, followed by 30 cycles of denaturation $\left(94^{\circ} \mathrm{C}, 0.5 \mathrm{~min}\right)$, annealing $\left(60^{\circ} \mathrm{C}\right.$ for $\mathrm{Id} 1,51^{\circ} \mathrm{C}$ for $\mathrm{Id} 2$ and $63^{\circ} \mathrm{C}$ for $\left.\mathrm{Id} 3,30 \mathrm{sec}\right)$, and extension $\left(72^{\circ} \mathrm{C}, 0.5 \mathrm{~min}\right)$, and then post-incubation

Table 1. Sequences of oligonucleotides used in this study

\begin{tabular}{|c|c|c|c|}
\hline \multirow[t]{12}{*}{ (A) } & GATA-4 & SSPN031 & $5^{\prime}$-gta ggc ctc tcc tgt g-3' \\
\hline & & SSPN033 & $5^{\prime}-\operatorname{cgc}$ tga tta cgc ggt gat-3' \\
\hline & $\alpha-\mathrm{MHC}$ & MHC S & 5'-gga aga gtg agc ggc gca tca agg-3' \\
\hline & & MHC A & $5^{\prime}-\mathrm{ctg}$ ctg gag agg tta ttc ctc g-3' \\
\hline & Id 1 & Id1f & $5^{\prime}-$ tgg acg agc agc agg tga acg-3' \\
\hline & & Id1r & $5^{\prime}$-gca ctg atc tcg ccg ttc agg-3' \\
\hline & Id 2 & $\mathrm{Id} 2 \mathrm{f}$ & 5'-agc ctt cag tcc ggt gag gtc c-3' \\
\hline & & $\mathrm{Id} 2 \mathrm{r}$ & 5 '-tca gat gec tgc aag gac agg-3' \\
\hline & Id 3 & $\mathrm{Id} 3 \mathrm{f}-2$ & $5^{\prime}$-ctc tac tct cca aca tga agg cg-3' \\
\hline & & $\operatorname{Id} 3 \mathrm{r}$ & $5^{\prime}$-agt gag ctc agc tgt ctg gat-3' \\
\hline & $\beta$-actin & YSactin S & $5^{\prime}$-gca gga gat ggc cac tgc cgc-3' \\
\hline & & YSactin A & $5^{\prime}$-tct cct tct gca tcc tgt cag c-3' \\
\hline \multirow[t]{6}{*}{ (B) } & Id 1 & YY001 & 5'-tt cat ATG AAG GTC GCC AGT GG-3' \\
\hline & & YY002 & 5'-cc TCA GCG ACA CAA GAT GCG-3' \\
\hline & Id 2 & YY003 & 5'-tt cat ATG AAA GCC TTC AGT C-3' \\
\hline & & YY004 & 5'-at TTA GCC ACA GAG TAC-3' \\
\hline & Id 3 & YY005 & 5'-tt cat ATG AAG GCG CTG AGC CCG-3' \\
\hline & & YY006 & 5'-gg TCA GTG GCAAAA GCT CCT CTT-3' \\
\hline \multirow[t]{3}{*}{ (C) } & M13F & & $5^{\prime}$-gta aaa cga cgg cca gt-3' \\
\hline & M13R & & $5^{\prime}$-gga aac agc tat gac cat g-3' \\
\hline & $\mathrm{T} 7$ primer & & $5^{\prime}$-taa tac gac tca cta tag-3' \\
\hline
\end{tabular}

In (B), an NdeI site (underlined) was introduced at the initiation codon in the sense primer (the primer S in Figure 1). The primer A in Figure 1 showed the antisense primer. Capital letters in (B) indicate the nucleotide residues identical to those in the coding region, while lower case letters indicate unrelated residues introduced. 
$\left.\left(72^{\circ} \mathrm{C}, 5 \mathrm{~min}\right)\right]$. The products were size-separated by $2 \%(\mathrm{w} / \mathrm{v})$ agarose gel-electrophoresis, and the amplified cDNA bands (454, 412 and 367 bp for Id1, Id2 and Id3, respectively) visualized with ethidium bromide were extracted with a GENECLEAN ${ }^{\circledR}$ III Kit (BIO101, Vista, CA, USA). The cDNAs were ligated into the pGEM T-easy vector (Promega) and then introduced into Escherichia coli TOP-10F'. The sequence of the cloned DNA was determined by the dideoxy chain-termination method (19) with a sequence primer (M13F or M13R) (Table 1C) and a BigDye ${ }^{\mathrm{TM}}$ Terminator v3.1 Cycle Sequencing Kit (Applied Biosystems, Waltham, MA, USA), using an ABI PRISM TM 310 Genetic Analyzer.

2.4. Construction of expression plasmids for Ids tagged with human influenza hemagglutinin (HA) and FLAG

The cDNA moiety of the Ids in the pGEM T-easy vector was excised with ApaI (Id1) or NsiI (Id2 and Id3), followed by Klenow treatment and then NdeI digestion. The fragment was inserted into pHA/FLAG(AS)-7 (20), which had been digested with $S p h$ I followed by Klenow treatment, and then digested with NdeI. The DNA sequence of the resulting plasmid, "Id in pHA/FLAG", was verified as described in 2.3. with a sequence primer (T7 primer or M13R) (Table 1C). The NotI HindIII fragment derived from "Id in pHA/FLAG" was further cloned into pDsRed2-N1 (CLONETECH, Mountain View, CA, USA). This expression plasmid was named pneo-HA/FLAG-Id. We further replaced the neomycin-resistance gene with that of hygromycin. The pGL4.14[luc2/Hygro] vector (Promega) containing the hygromycin-resistance gene was treated with $B g l I I$ and BamHI, and the large fragment was self-ligated, resulting in deletion of the luciferase gene moiety. Into the EcoRV site of the multi-cloning site of the self-ligation product (phyg), the HA-FLAG-Id portion together with promoter from pneo-HA/FLAG-Id were inserted; the fragment being obtained on NsiI digestion followed by Klenow treatment and $S s p$ I digestion. The procedure is schematically shown in Figure 1. The molecular biological methods for DNA manipulations were based on standard procedures (21).

2.5. Transfection of expression plasmids for Ids tagged with HA and FLAG

We first expressed the tagged Id proteins (HA/FLAGIds) transiently by means of the diethylaminoethyl (DEAE)-dextran method (22) to verify the expression of tagged Ids derived from the plasmid constructs; Cos1 cells (ATCC, Manassas, VA, USA) were grown in Dulbecco's modified Eagle medium (DMEM) (GIBCO BRL) supplemented with 7\% (v/v) FBS. Cells $(5 \times$ $10^{5}$ cells) in $5 \mathrm{~mL}$ medium were plated onto a $\Phi 6$ $\mathrm{cm}$ dish. Into each dish the plasmid construct was introduced at a concentration of $2.5 \mu \mathrm{g} / \mathrm{dish}$. Cells were

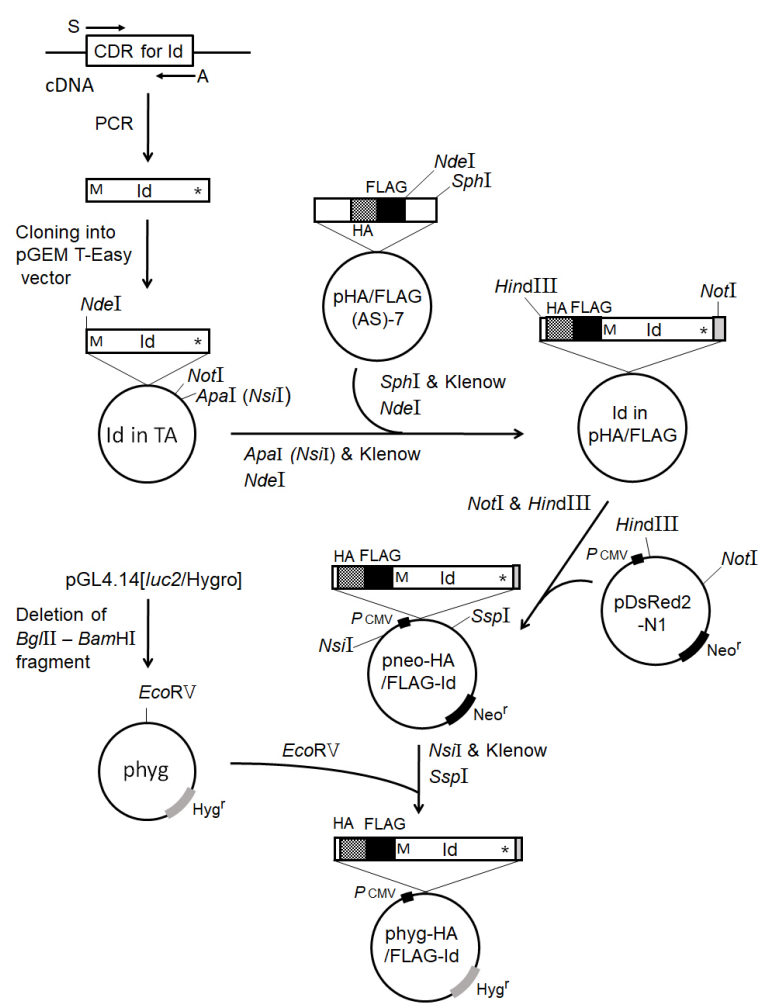

Figure 1. Construction of expression plasmids for Id1, Id2 and Id3 with an amino-terminal tandem HA/FLAG-tag. The coding regions (CDRs) for Id 1 , Id 2 and Id 3 were cloned from cDNAs prepared from differentiated P19CL6 cells, and inserted into pGEM T-Easy vector (Id in TA). The primer pairs listed in Table 1B were designed from the registered cDNA sequences; NM_010495 (Id1), NM_010496 (Id2), and NM_008321 (Id3), respectively. The expression plasmids for Ids with an amino-terminal HA/FLAG-tag (pneo-HA/FLAG-Id) were constructed as described under Materials and Methods. The neomycin-resistance gene $\left(\mathrm{Neo}^{\mathrm{r}}\right)$ was further substituted with the hygromycin-resistance gene $\left(\mathrm{Hyg}^{\mathrm{r}}\right)$ to produce phyg-HA/FLAG-Id. The initiation and termination codons for Id are indicated by "M" and "*", respectively. The coding regions for the HA (YPYDVPDYA) and and FLAG (DYKDDDDK) peptide moieties are schematically shown by mesh and black shading, respectively. HA/FLAG-Id was transcribed under the cytomegalovirus (CMV) promoter $\left(P_{\mathrm{CMV}}\right)$.

treated with chloroquine followed by glycerol, and then further cultured for 2 days. The whole cell extract for immunoprecipitation was prepared from duplicate samples. Protein concentrations were determined with a BioRad Protein Assay Kit (Hercules, CA, USA) using bovine serum albumin (Fraction V) (Sigma) as a standard (23).

We further isolated P19CL6 clones that express tagged Ids stably by the calcium-phosphate method (21); briefly, cells $\left(5 \times 10^{5}\right.$ cells) were plated onto a $\Phi 6 \mathrm{~cm}$ dish. On the next day, the DNA solution was poured onto the culture medium and left for $4 \mathrm{hr}$. The medium was removed and washed with phosphate-buffered saline [10 mM phosphate buffer (pH7.2), $137 \mathrm{mM}$ $\mathrm{NaCl}, 3 \mathrm{mM} \mathrm{KCl}$ (PBS). Cells were further cultured in fresh medium for $24 \mathrm{hr}$, and then neomycin (G418) (100 $\mu \mathrm{g} / \mathrm{mL}$ ) (Nacalai, Kyoto, Japan) or hygromycin (300 $\mu \mathrm{g} / \mathrm{mL}$ ) (Wako) was added. On the following day, cells were plated onto 2 dishes $(\Phi 10 \mathrm{~cm})$ containing the 
antibiotic. After $\sim 12$ days, single colonies were isolated. A whole cell extract was prepared from a confluent culture of undifferentiated clones grown in two $\Phi 6 \mathrm{~cm}$ dishes.

2.6. Preparation of a whole cell extract and immunoprecipitation

After washing with ice-cold PBS three times, cells were suspended in $1 \mathrm{~mL} 20 \mathrm{mM}$ tris(hydroxymethyl) aminomethane (Tris)- $\mathrm{HCl}$ ( $\mathrm{pH} 7.5$ ), $150 \mathrm{mM} \mathrm{NaCl}, 2$ $\mathrm{mM}$ ethylenediaminetetraacetic acid containing $10 \mu \mathrm{g} /$ $\mathrm{mL}$ leupeptin, $10 \mu \mathrm{g}$ pepstatin A and 1\% (v/v) NP-40 [TNE (+)] and kept on ice for $30 \mathrm{~min}$. All the following procedures were carried out at $4^{\circ} \mathrm{C}$. The cell suspension was sheered through a $25 \mathrm{G}$ needle 10 times, and then centrifuged $(12,000 \times \mathrm{g}, 30 \mathrm{~min})$. The supernatant was used as the whole cell extract.

The Protein G Sepharose beads (GE Healthcare, Chicago, IL, USA) was pre-washed twice with TNE $(+)$ and then centrifuged $(2,000 \times \mathrm{g}, 5 \mathrm{~min})$. The whole cell extract was incubated for $1 \mathrm{hr}$ in a Mini Disk Rotor BC-710 (BIO CRAFT, Tokyo, Japan) with a 30 $\mu \mathrm{L}$ bed volume of pre-washed Protein G Sepharose beads. The supernatant was incubated on a Rotor for $1 \mathrm{hr}$ with $5 \mu \mathrm{L}$ of Monoclonal anti-HA (HA-7) (Sigma), and then further incubated in a Rotor with a $50 \mu \mathrm{L}$ bed volume of pre-washed Protein G Sepharose beads for $1 \mathrm{hr}$. The beads were precipitated $(2,000 \times$ g, $5 \mathrm{~min}$ ) and then washed five times (three times by rotation and then twice without rotation) with 500 $\mu \mathrm{L} 20 \mathrm{mM}$ Tris-HCl (pH 7.5), $150 \mathrm{mM} \mathrm{NaCl}, 2 \mathrm{mM}$ ethylenediaminetetraacetic acid (TNE). The recovered immuno-complex was heated at $95^{\circ} \mathrm{C}$ for 5 min together with $15-20 \mu \mathrm{L}$ of $2 \times$ sample buffer for sodium dodecyl sulfate (SDS)-polyacrylamide gel-electrophoresis (24).

2.7. SDS-polyacrylamide gel-electrophoresis and Western blotting

All the solubilized protein was subjected to SDSpolyacrylamide gel-electrophoresis [mini-gel (10 $\mathrm{cm} \times 10 \mathrm{~cm}), 1 \mathrm{~mm}$ thickness, consisting 3\%(w/v) stacking gel $(60 \mathrm{~V})$ and $18 \%(\mathrm{w} / \mathrm{v})$ separation gel $(100$ $\mathrm{V})$ ] (24), and then electro-blotted [200 mA, $90 \mathrm{~min}$; ATTO Model-AE6675 (ATTO, Tokyo, Japan)] onto an Immobilon ${ }^{\mathrm{TM}}$-P membrane [Millipore (Billerica, MA, USA) polyvinylidene difluoride (PVDF) membrane (0.45 $\mu \mathrm{m})$, IPVH00010] (25). The filter was washed with PBS and then blocked $1 \mathrm{hr}$ at $4{ }^{\circ} \mathrm{C}$ with PBS plus $0.1 \%(\mathrm{v} / \mathrm{v})$ Tween $20(\mathrm{PBS}-\mathrm{T})$ containing 5\% (w/v) skim-milk (BD, Franklin Lakes, NJ, USA). The filter was washed with PBS-T and then reacted for $2 \mathrm{hr}$ at room temperature with ANTI-FLAG M2 ${ }^{\circledR}$ monoclonal antibody-peroxidase conjugate (Sigma) $(\times 1,500$ diluted). Chemiluminescence was detected with an ECL Western blotting kit (GE Healthcare) using Scientific
Imaging Film (KODAK, Rochester, NY, USA).

\subsection{Chemicals}

Restriction enzymes were obtained from New England Biolabs (Ipswich, MA, USA) and Toyobo. The Klenow enzyme, T4 DNA ligase (Ligation Kit Ver2.1), and Agarose-LE Classic Type were provided by TaKaRa. Tween 20 and chloroquine diphosphate were obtained from Nacalai. DEAE-dextran, NP-40, leupeptin and pepstatin A were from Sigma. Oligonucleotides were purchased from Gene Design Inc. (Ibaraki, Osaka, Japan). All other chemicals used were of the highest grade commercially available.

\section{Results}

\subsection{Construction of expression plasmids for Ids}

The cDNAs for mouse Ids (Id1, Id2 and Id3) were cloned from P19CL6 cells by means of reverse transcription PCR (RT-PCR) and then inserted into a mammalian expression plasmid pDsRed2-N1. To detect ectopic expression, we introduced a HA/FLAG-tag at the amino terminus of each Id. The neomycin-resistance marker was also replaced with that of hygromycin (Figure 1). Plasmids were introduced into Cos-1 cells, and the Id proteins transiently expressed were detected by Western blotting to verify their molecular sizes. Since we sometimes experienced difficulty in detecting the tagged Id proteins in a whole cell extract, an immunoprecipitation method was developed, as shown under Materials and Methods. The HA/FLAG-Id in the whole cell extract was first immunoprecipitated with anti-HA antibody and then detected by means of Western blotting with anti-FLAG antibody. As shown in Figure 2, the calculated molecular size of the tagged-Id (see legend to Figure 2) was not significantly different from its molecular size on the gel.

\subsection{Stable expression of Ids in P19CL6 cells}

The expression plasmids for tagged Ids were introduced into P19CL6 cells and neomycin-resistance colonies were isolated. However, most of the resistant clones did not express HA/FLAG-Id in spite of several trials of transfection. Typical results are shown in Figures $3 \mathrm{~A}$ and $3 \mathrm{~B}$; two clones for tagged $\mathrm{Id} 1\left(\mathrm{Id} 1_{\mathrm{A} 5}\right.$ and $\left.\mathrm{Id} 1_{\mathrm{B} 7}\right)$ and one for tagged $\mathrm{Id} 3\left(\mathrm{Id} 3_{\mathrm{A} 3}\right)$ were obtained in two separate transfection experiments. However, clones for tagged Id 2 could not be obtained. We also did not obtain a clone from hygromycin-resistant colonies.

3.3. Transcription level of GATA-4 under differentiation condition for P19CL6 cells

As already reported, many preceding studies involving 


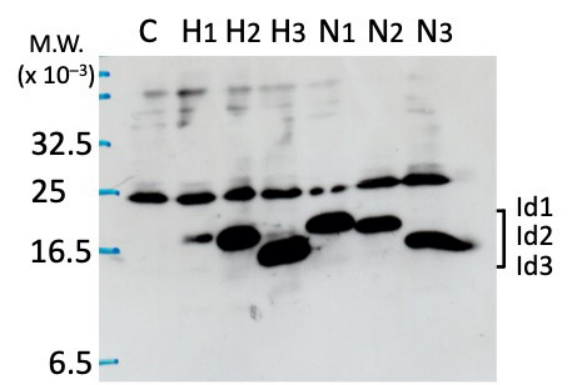

Figure 2. Transient expression of Id1, Id2, or Id3 tagged with a HA/FLAG peptide in Cos-1 cells. Cos-1 cells were transfected with the expression plasmid for either tagged Id1, Id2 or Id 3 by means of the DEAE-dextran method $\mathrm{H}_{1}$ (phyg-HA/FLAG-Id1), $\mathrm{H}_{2}$ (phyg-HA/FLAG-Id2), $\mathrm{H}_{3}$ (phyg-HA/FLAG-Id3), $\mathrm{N}_{1}$ (pneo-HA/ FLAG-Id1), $\mathrm{N}_{2}$ (pneo-HA/FLAG-Id2), $\mathrm{N}_{3}$ (pneo-HA/FLAG-Id3), and $\mathrm{C}$ (without plasmid)]. Cells were grown for 2 days, and then the transiently expressed HA/FLAG-Id protein in the whole cell extract was immunoprecipitated with anti-HA antibody. HA/FLAG-Id protein was detected by Western blotting with peroxidase conjugated anti-FLAG antibody after SDS-polyacrylamide gel-electrophoresis as described under Materials and Methods. Chemiluminescence was detected after $15 \mathrm{~min}$ exposure. The average molecular mass of the tagged Id protein was calculated with GENETYX-MAC GENETIC INFORMATION PROCESSING SOFTWARE (GENETYX Corporation, Tokyo, Japan); HA/FLAG-Id1, 19.1 kDa; HA/FLAGId2, $18.5 \mathrm{kDa}$; and HA/FLAG-Id3, $16.7 \mathrm{kDa}$. The values were the sums of the amino acid residues of the native Id (148, 134 and 119 residues for Id1, Id2 and Id3, respectively) and HA/FLAG peptide (31 residues) (20). The Id1 used in this study was a smaller isoform produced by removing a coding intron (49).

P19 and P19CL6 cells revealed that the transcription of GATA-4 gene starts at around 4 days under differentiation conditions, that of the genes for the components of cardiac muscle following later $(7,26-28)$. Figure 4 (left) shows that GATA-4 mRNA was actually detected within 4 days after DMSO addition and that of $\alpha$-MHC appeared at 8 days weakly and at 12 days clearly. However, transcription of the GATA-4 gene did not occur in $\operatorname{Id} 1_{\mathrm{A} 5}$ and $\operatorname{Id} 3_{\mathrm{A} 3}$ cells even in the presence of DMSO, ectopically HA/FLAG-Id 1 and HA/FLAGId3 being expressed, respectively (Figure 4, middle and right). As the transcription of cardiac muscle genes such as $\alpha-M H C, \beta-M H C$, cardiac troponin $\mathrm{C}(c T p C)$, atrial myosin light-chain $1\left(M L C-1_{A}\right)$ and ventricular MLC-1 $\left(M L C-1_{V}\right)$ is positively regulated by GATA4 (29), the expression of $\alpha$-MHC was not induced in $\operatorname{Id} 1_{\mathrm{A} 5}$ and $\mathrm{Id} 3_{\mathrm{A} 3}$ cells without GATA-4 expression (Figure 4). It must be further noted that the GATA-4 and $\alpha-M H C$ genes were also repressed in $\operatorname{Id} 1_{\mathrm{B} 7}$ cells, similar to in Figure 4 (middle) under differentiation condition (not shown), which may suggest that ectopic Id1 reproducibly inhibits GATA-4 gene transcription under our experimental condition.

The Ids were transcribed even in an undifferentiated state, as shown at Day 0 in Figure 4, as the Ids were usually detected in the control samples without DMSO $(17,28,30)$. Regarding the behavior of the expression pattern in our study, the mRNA level of Id2 was clearly

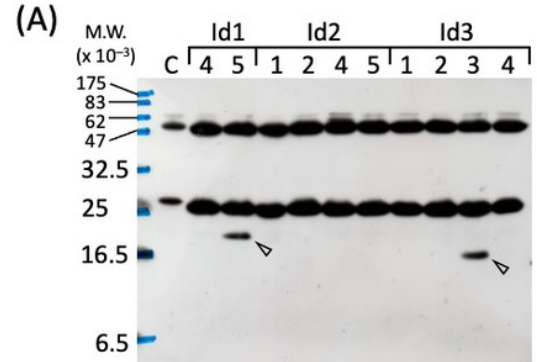

(B)

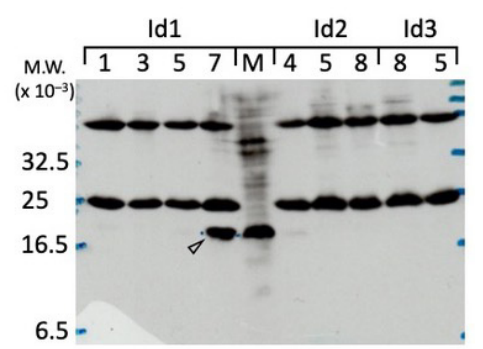

Figure 3. Detection of Ids tagged with a HA/FLAG peptide stably expressed in P19CL6 cells. (A) P19CL6 cells were transfected with the expression plasmid for either tagged Id1, Id 2 or Id 3 by means of the calcium-phosphate method [Id1 (pneo-HA/FLAG-Id1), Id2 (pneo-HA/ FLAG-Id2), Id3 (pneo-HA/FLAG-Id3), and C (P19CL6 cells without transfection)] as described under Materials and Methods. Six colonies resistant to neomycin were isolated from each transfection. The whole cell extract of each clone was treated with anti-HA antibody, and the immune-precipitated HA/FLAG-Id was detected by means of Western blotting with anti-FLAG antibody after SDS-polyacrylamide gelelectrophoresis. Chemiluminescence was detected after $1 \mathrm{hr}$ exposure. The numbers of clones from each expression plasmid are indicated above. (B) P19CL6 cells were transfected similarly to as described in (A), and eight colonies resistant to neomycin were isolated from each transfection. M, whole cell extract ( $20 \mu \mathrm{g}$ protein) prepared from Cos1 cells transiently expressing the Id1 expression plasmid (pneo-HA/ FLAG-Id1). Open triangles in (A) and (B) indicated the tagged Id proteins (HA/FLAG-Id1 and HA/FLAG-Id3). The positive clones are denoted as clone $\operatorname{Id} 1_{\mathrm{A} 5}$, clone $\mathrm{Id} 1_{\mathrm{B} 7}$ and clone $\mathrm{Id} 3_{\mathrm{A} 3}$, respectively, in the text. Id proteins could not be detected in the rest of the clones not indicated in the figure (not shown).

increased in a later stage of culture in the presence of DMSO independently of the forced expression of Id1 and Id3 (Days 8 and 12 in Figure 4). The mRNA levels of Id1 and Id3 seemed to increase or to be maintained during culture, although those of the transcripts for Ids in $I d 1_{A 5}$ cells decreased immediately after differentiation.

\section{Discussion}

Transcription of the GATA-4 gene in heart could be activated by ubiquitous E-box binding proteins ( 9 ) and heart-specific upstream enhancer (G2), which is a direct target of Forkhead box (Fox) and GATA transcription factors (31). Ids are known to directly inhibit ubiquitous E-box binding bHLH transcription factors such as Transcription factor 3 (Tcf3 known as E2A) (16) and UCF2 (32), and indirectly Foxa2 (16). Furthermore, Id proteins bind to GATA-4 and inhibit its DNA binding to the GATA motif (17). These observations suggest that 


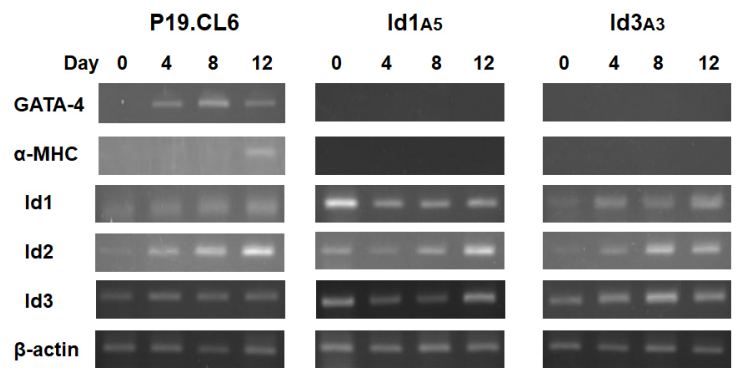

Figure 4. Inhibition of $G A T A-4$ gene transcription under differentiation condition in the P19CL6 cells with overexpressed Id1 and Id3 tagged with a HA/FLAG peptide. P19CL6 cells and clones $\mathrm{Id}_{\mathrm{A} 5}$ and $\mathrm{Id}_{\mathrm{A} 3}$ were cultured in the presence of $1 \%$ DMSO. Total RNA was prepared on the indicated days after the addition of DMSO. The mRNA levels (GATA-4, $\alpha$-MHC, Id1, Id2, Id 3 and $\beta$-actin) were determined by means of RT-PCR under semi-quantitative conditions using the primer pairs shown in Table 1A. The products $(537,302,244,351,329$, and 278 bp, respectively) were analyzed by $2 \%(\mathrm{w} / \mathrm{v})$ agarose gel electrophoresis (see Materials and Methods). The primer pairs for GATA-4, $\alpha$-MHC, and $\beta$-actin were designed from the registered cDNA sequences; NM_008092 (GATA-4), M76601 ( $\alpha$-MHC), and NM_007393 ( $\beta$-actin), respectively.

the increased expression of Id1 and Id3 likely inhibits GATA-4 transcription and the GATA-4 function, which results in inhibition of expression of cardiac muscle genes and differentiation of P19CL6 cells.

A negative feedback regulatory loop between Ids and cardiac transcription factors such as GATA-4 and Nkx2.5 is proposed since transiently expressed these transcription factors induce Id2 expression in rat and mouse cardiomyocyte precursor cell lines (28). Such induction of Id2 was detected in our experiment (Figure 4 , left), although increases of Id2 transcripts were detected in the presence of DMSO without GATA-4 expression (Figure 4, middle and right), possibly due to participation of DMSO-inducible factor(s) hitherto unidentified (26).

P19-derived cardiomyocytes resemble embryonic cardiomyocytes (6). The E-box binding Hey1 and Hey2 bHLH transcription factors (different nomenclature summarized in ref. 33), which are expressed developmentally in atrial and ventricular compartments (33), are repressors of GATA-4 (34). Although Id1 could interact with Hey1 (35), it is unlikely that Ids cancel repression of the GATA-4 gene through binding to Hey1 and Hey2 upon DMSO addition since P19CL6 cells do not express Hey1 and Hey2 in the absence of DMSO (Figure S1, http://www.ddtjournal.com/ action/getSupplementalData.php? ID=78). Actually, the transcript of Heyl increased starting from 4 days of differentiation (27).

Although transcription factors GATA-4, myocytespecific enhancer factor $2 \mathrm{C}$ (Mef2c), Nkx2.5 and Tbx5, which mutually interact (6), could stimulate cardiomyocyte differentiation of P19 and P19CL6 cells $(7,36,37)$, signaling pathways further govern the expression and function of these transcription factors. Bone morphogenetic protein (BMP) stimulates differentiation of P19CL6 cells through the Smad and TAK1 (a member of the mitogen-activated protein kinase kinase kinase) pathways together with DMSOinducible factors independent of BMP signaling (26). Furthermore, the hedgehog, Wnt and Notch signals may participate in cardiac development $(33,38,39)$. BMP-mediated inhibition of Wnt signal stimulated the commitment of cardiac precursor cells to become cardiomyocytes (39). Although the BMP signal also induces Ids (35), Ids can stimulate cardiomyocyte proliferation $(30,40,41)$. The relative contents of Ids and relevant transcription factors would govern the growth and differentiation of cardiac cells since single cell analysis of fate conversion of fibroblasts into cardiomyocytes suggested a strong anti-correlation of $I d$ genes with those of GATA-4, Mef2c and Tbx5 (42).

Ectopic p204 could partially substitute for DMSO in inducing the differentiation of P19 cells and concomitantly stimulate nuclear export of Ids resulting in their degradation by proteasomes $(17,43)$. Thus, not only transcription but also cellular localization of Id proteins should be carefully examined. Several modes of regulation by bHLH proteins and Ids have been also postulated (44), and their context-dependent regulatory circuits including miRNAs were proposed $(35,45)$. Culture conditions might also influence the regulatory circuits since Id expression and cardiac differentiation could be affected by serum (46) and the insulin dose (47), respectively. Since cardiomyocyte regeneration is clinically important for the repair of a damaged heart (48), further study of the molecular mechanisms underlying fine-tuning of such regulatory circuits in which Ids and transcription factors including GATA-4 participate may be helpful for improvement of cardiac cell therapy.

\section{Acknowledgements}

This research was supported in part by the JSPS (Grantin-Aid for Scientific Research (B), 14370744) to M. M.

\section{Funding: None.}

Conflict of Interest: The authors have no conflicts of interest to disclose.

\section{References}

1. Takaoka K, Hamada H. Cell fate decisions and axis determination in the early mouse embryo. Development. 2012; 139:3-14.

2. Kelly RG, Buckingham ME, Moorman AF. Heart fields and cardiac morphogenesis. Cold Spring Harb Perspect Med. 2014; 4:a015750.

3. Aronson BE, Stapleton KA, Krasinski SD. Role of GATA factors in development, differentiation, and homeostasis of the small intestinal epithelium. Am J Physiol Gastrointest 
Liver Physiol. 2014; 306:G474-G490.

4. Heikinheimo M, Scandrett JM, Wilson DB. Localization of transcription factor GATA-4 to regions of the mouse embryo involved in cardiac development. Dev Biol. 1994; 164:361-373.

5. Kodo K, Yamagishi H. Current insight into genetics of congenital heart diseases: GATA and T-box cardiac transcription factors as the hotspot pathogenesis. J Pediatr Cardiol Card Surg. 2017; 1:18-27.

6. van der Heyden MAG, Defize LHK. Twenty-one years of P19 cells: what an embryonal carcinoma cell line taught us about cardiomyocyte differentiation. Cardiovasc Res. 2003; 58:292-302.

7. Grépin C, Robitaille L, Antakly T, Nemer M. Inhibition of transcription factor GATA-4 expression blocks in vitro cardiac muscle differentiation. Mol Cell Biol. 1995; 15:4095-4102.

8. Guittot SM, Bouchard MF, Robert-Grenon J-P, Robert C, Goodyer CG, Silversides DW, Viger RS. Conserved usage of alternative 5' untranslated exons of the GATA4 gene. PLoS ONE. 2009; 4:e8454.

9. Guittot SM, Prud'homme B, Bouchard MF, Bergeron F, Daems C, Tevosian SG, Viger RS. GATA4 autoregulates its own expression in mouse gonadal cells via its distal $1 \mathrm{~b}$ promoter. Biol Reprod. 2014; 90:1-15.

10. Ishibashi T, Yokura Y, Ohashi K, Yamamoto H, Maeda M. Conserved GC-boxes, E-box and GATA motif are essential for GATA4 gene expression in P19CL6 cells. Biochem Biophys Res Commun. 2011; 413:171-175.

11. Sab AB, Bouchard M-F, Béland M, Prud'homme B, Souchkova O, Viger RS, Pilon N. An Ebox element in the proximal Gata4 promoter is required for Gata4 expression in vivo. PLoS One. 2011; 6:e29038.

12. Srivastava D, Cserjesi P, Olson EN. A subclass of bHLH proteins required for cardiac morphogenesis. Science. 1995; 270:1995-1999.

13. Xu H, Yang C, Wang Y, Tian J, Zhu J. Histone modifications interact with DNA methylation at the GATA4 promoter during differentiation of mesenchymal stem cells into cardiomyocyte-like cells. Cell Prolif. 2016; 49:315-329.

14. $\mathrm{Hu} \mathrm{W}, \mathrm{Xin} \mathrm{Y}, \mathrm{Hu}$ J, Sun $\mathrm{Y}$, Zhao Y. Inhibitor of DNA binding in heart development and cardiovascular diseases. Cell Commun Signal. 2019; 17:51.

15. Yokota Y, Mori S. Role of Id family proteins in growth control. J Cell Physiol. 2002; 190:21-28.

16. Cunningham TJ, Yu MS, McKeithan WL, et al. Id genes are essential for early heart formation. Genes Dev. 2017; 31:1325-1338

17. Ding B, Liu C-J, Yu J, Kong W, Lengyel P. p204 protein overcomes the inhibition of the differentiation of P19 murine embryonal carcinoma cells to beating cardiac myocytes by Id proteins. J Biol Chem. 2006; 281:1489314906.

18. Saiki RK, Gelfand DH, Stoffel S, Scharf SJ, Higuchi R, Horn GT, Mullis KB, Erlich HA. Primer-directed enzymatic amplification of DNA with a thermostable DNA polymerase. Science. 1988; 239:487-491.

19. Sanger F, Coulson AR, Barrell BG, Smith AJH, Roe BA. Cloning in single-stranded bacteriophage as an aid to rapid DNA sequencing. J Mol Biol. 1980; 143:161-178.

20. Chiang C-M, Ge H, Wang Z, Hoffman A, Roeder RG. Unique TATA-binding protein-containing complexes and cofactors involved in transcription by RNA polymerases II and III. EMBO J. 1993; 12:2749-2762.
21. Sambrook J, Fritsch EF, Maniatis T. Molecular Cloning: A Laboratory Manual, 2nd ed., Cold Spring Harbor Laboratory, Cold Spring Harbor. 1989.

22. Takeda M, Obayashi K, Kobayashi A, Maeda M. A unique role of an amino terminal 16-residue region of long-type GATA-6. J Biochem. 2004; 135:639-650.

23. Bradford MM. A rapid and sensitive method for the quantitation of microgram quantities of protein utilizing the principle of protein-dye binding. Anal Biochem. 1976; $72: 248-254$

24. Laemmli UK. Cleavage of structural proteins during the assembly of the bacteriophage T4. Nature. 1970; 227:680685.

25. Towbin H, Staehelin T, Gordon J. Electrophoretic transfer of proteins from polyacrylamide gels to nitrocellulose sheets: procedure and some applications. Proc Natl Acad Sci USA. 1979; 76:4350-4354.

26. Monzen K, Hiroi Y, Kudoh S, Akazawa H, Oka T, Takimoto E, Hayashi D, Hosoda T, Kawabata M, Miyazono K, Ishii S, Yazaki Y, Nagai R, Komuro I. Smads, TAK1, and their common target ATF-2 play a critical role in cardiomyocyte differentiation. J Cell Biol. 2001; 153:687-698.

27. Peng C-F, Wei Y, Levsky JM, McDonald TV, Childs G, Kitsis RN. Microarray analysis of global changes in gene expression during cardiac myocyte differentiation. Physiol Genomics. 2002; 9:145-155.

28. Lim JY, Kim WH, Kim J, Park SI. Induction of Id2 expression by cardiac transcription factors GATA4 and Nkx2.5. J Cell Biochem. 2008; 103:182-194.

29. Molkentin JD, Kalvakolanu DV, Markham BE. Transcription factor GATA-4 regulates cardiac musclespecific expression of the $\alpha$-myosin heavy-chain gene. Mol Cell Biol. 1994; 14:4947-4957.

30. Meng Q, Jia Z, Wang W, Li B, Ma K, Zhou C. Inhibitor of DNA binding 1 (Id1) induces differentiation and proliferation of mouse embryonic carcinoma P19CL6 cells. Biochem Biophys Res Commun. 2011; 412:253259.

31. Rojas A, De Val S, Heidt AB, Xu S-M, Bristow J, Black BL. Gata4 expression in lateral mesoderm is downstream of BMP4 and is activated directly by Forkhead and GATA transcription factors through a distal enhancer element. Development. 2005; 132:3405-3417.

32. Simões-Sato AY, Antonioli E, Tambellini R, Campos H. ID1 inhibits USF2 and blocks TGF- $\beta$-induced apoptosis in mesangial cells. Am J Physiol Renal Physiol. 2011; 301:F1260-F1269.

33. Fischer A, Leimeister C, Winkler C, Schumacher N, Klamt B, Elmasri H, Steidl C, Maier M, Knobeloch K-P, Amann K, Helosch A, Sendtner M, Gessler M. Hey bHLH factors in cardiovascular development. Cold Spring Harb Symp Quant Biol. 2002; 67:63-70.

34. Fischer A, Klattig J, Kneitz B, Diez H, Maier M, Holtmann B, Englert C, Gessler M. Hey basic helix-loophelix transcription factors are repressors of GATA4 and GATA6 and restrict expression of the GATA target gene ANF in fetal hearts. Mol Cell Biol. 2005; 25:8906-8970.

35. Itoh $\mathrm{F}$, Itoh $\mathrm{S}$, Goumans M-J, Valdimarsdottir G, Iso T, Dotto GP, Hamamori Y, Kedes L, Kato M, ten Dijke P. Synergy and antagonism between Notch and BMP receptor signaling pathways in endothelial cells. EMBO J. 2004; 23:541-551.

36. Skerjanc IS, Petropoulos H, Ridgeway AG, Wilton S. Myocyte enhancer factor $2 \mathrm{C}$ and $\mathrm{Nkx} 2-5$ up-regulate each 
other's expression and initiate cardiomyogenesis in P19 cells. J Biol Chem. 1998; 273:34904-34910.

37. Hiroi Y, Kudoh S, Monzen K, Ikeda Y, Yazaki Y, Nagai R, Komuro I. Tbx5 associates with Nkx2-5 and synergistically promotes cardiomyocyte differentiation. Nat Genet. 2001; 28:276-280.

38. Gianakopoulos PJ, Skerjanc IS. Hedgehog signaling induces cardiomyogenesis in P19 cells. J Biol Chem. 2005; 280:21022-21028.

39. Jain R, Li D, Gupta M, et al. Integration of Bmp and Wnt signaling by Hopx specifies commitment of cardiomyoblasts. Science. 2015; 348:aaa6071.

40. Ball AJ, Levine F. Telomere-independent cellular senescence in human fetal cardiomyocytes. Aging Cell. 2005; 4:21-30.

41. Cheng YY, Yan YT, Lundy DJ, Lo AA, Wang YP, Ruan S-C, Lin PJ, Hsieh PC. Reprogramming-derived gene cocktail increases cardiomyocyte proliferation for heart regeneration. EMBO Mol Med. 2017; 9:251-264.

42. Liu Z, Wang L, Welch JD, Ma H, Zhou Y, Vaseghi HR, Yu S, Wall JB, Alimohamadi S, Zheng M, Yin C, Shen W, Prins JF, Liu J, Qian L. Single-cell transcriptomics reconstructs fate conversion from fibroblast to cardiomyocyte. Nature. 2017; 551:100-104.

43. Ding B, Liu C-J, Huang Y, Hickey RP, Yu J, Kong W, Lengyel P. p204 is required for the differentiation of P19 murine embryonal carcinoma cells to beating cardiac myocytes: its expression is activated by the cardiac GATA4, NKX2.5, and TBX5 proteins. J Biol Chem. 2006; 281:14882-14892.

44. Yokota Y. Id and development. Oncogene. 2001; 20:82908298.

45. Meier-Stiegen F, Schwanbeck R, Bernoth K, Martini
S, Hieronymus T, Ruau D, Zenke M, Just U. Activated Notch1 target genes during embryonic cell differentiation depend on the cellular context and include lineage determinants and inhibitors. PLoS One. 2010; 5:e11481.

46. Springhorn JP, Ellingsen O, Berger H-J, Kelly RA, Smith TW. Transcriptional regulation in cardiac muscle: coordinate expression of Id with a neonatal phenotype during development and following a hypertrophic stimulus in adult rat ventricular myocyte in vitro. J Biol Chem. 1992; 267:14360-14365.

47. Li WY, Song YL, Xiong CJ, Lu PQ, Xue LX, Yao CX, Wang WP, Zhang SF, Zhang SF, Wei QX, Zhang YY, Zhao JM, Zang MX. Insulin induces proliferation and cardiac differentiation of P19CL6 cells in a dose-dependent manner. Develop Growth Differ. 2013; 55:676-686.

48. Zhang Y, Mignone J, MacLellan WR. Cardiac regeneration and stem cells. Physiol Rev. 2015; 95:1189-1204.

49. Springhorn JP, Singh K, Kelly RA, Smith TW. Posttranscriptional regulation of Idl activity in cardiac muscle: alternative splicing of novel Id1 transcript permits homodimerization. J Biol Chem. 1994; 269:5132-5136.

Received July 24, 2021; Revised August 4, 2021; Accepted August 9, 2021

*Address correspondence to:

Masatomo Maeda, Graduate School of Pharmaceutical Sciences, Osaka University, Yamada-oka 1-6, Suita, Osaka 565-0871, Japan.

E-mail: qqpe4zr9k@clock.ocn.ne.jp

Released online in J-STAGE as advance publication August 20, 2021. 